\title{
PROBLEMS OF THE SIMULATION AND MODELING THE LIGHTNING PROTECTION OF HIGH STRUCTURES
}

\author{
${ }^{1}$ Zoltán TÓTH*, ${ }^{2}$ István KISS, ${ }^{3}$ Bálint NÉMETH \\ Department of Electric Power Engineering, Faculty of Electrical Engineering and Informatics \\ Budapest University of Technology and Economics, Egry J. u. 18, H-1111 Budapest, Hungary \\ e-mail: ${ }^{1}$ toth.zoltan@vet.bme.hu, ${ }^{2}$ kiss.istvan@vet.bme.hu, ${ }^{3}$ nemeth.balint@vet.bme.hu
}

Received 15 January 2018; accepted 14 January 2019

\begin{abstract}
There are existing techniques for building; lightning protection for tall buildings, however, the design of an effective system requires a different approach from the typical one developed for houses or normal size buildings. This category includes skyscrapers and wind turbines, whose number is rapidly increasing. The number of upward, positive strikes and ones that strike into the side of the tower are not negligible. In the latter case, the increasing nominal power increases the dimensions of the turbine, and the risk of a strike, too. Therefore, their expected lifetime may be shortened, and the classical space calculation models have to be rethought and refined.

In this work, the probability modulated attractive volume method is applied to examine wind turbines with one and two receptors. Besides that, some investigations of high buildings for negative and positive lightning were evaluated to determine the change of the attractive space.

For the risk calculation, the knowledge of the ratio of the striking distances is necessary, which can be determined based on laboratory measurements. The deficiency of each arrangement is demonstrated through simulations and laboratory measurements.
\end{abstract}

Keywords: Lightning protection, Upward discharges, Modeling, Simulation, Probability modulated attractive volume, Wind turbines, High structures

\section{Introduction}

The number of the strikes into the blades is increasing with the growing size of the wind turbines. To avoid the damages caused by direct lightning strike, the developing

\footnotetext{
${ }^{*}$ Corresponding Author
} 
wind turbine constructions had to include novel lightning protection solutions, as well. Horváth's Probability Modulated Attractive Volume (PMAV) method offers a suitable solution [1], [2], [3] to select a proper lightning protection system.

Previously it was assumed that the air-terminators (receptors) at the top of the blades, which are connected to the shaft of the rotor by a conductor inside the insulating plastic layer [4], are satisfactory. There are many constructions to lead the lightning current continuously to the ground between the baluster and the rotating shaft. One of them is when the bearing is a part of the termination system and the whole current passes over on it. Other method is to spare the bearing; the lightning current is earthed through a bridging branch [5].

The experiments show that there was several lightning caused damage on the blades despite of the lightning protection satisfying the standards. Some of the damages were drastic, while others did not cause any immediate failure, but after long run caused further damages through material ageing, making proper operation later impossible [6].

Even though nowadays the blades are equipped with more receptors [7], numerous strikes hit directly into the blades [8]. Most of the lightning strikes, which strike the wind turbines, hit the receptors; still the number of the hits into the blade or into the tower is not negligible. The latter strikes over the plastic layer (under this run the metallic conductor) or runs on the surface until the arrester.

By the application of Horváth's theory [1], [2], [3] it is possible to calculate the number of the striking frequency, i.e. the number of strikes into the side of the blade per year.

\section{The PMAV method}

The PMAV is a method to determine the expected striking frequency for a given object. The basis of the method is similar to the Electro-Geometric Model (EGM) method [9]. To determine the correlation between the striking distance and the magnitude of the lightning current, there are various methods, as well [3].

From a striking point, the lightning strikes into an object with only a certain probability. Let this value be denoted by $\beta$. In the reality the striking factor, $\beta$ is changing continuously between 0 and 1 . A simplified approach is to consider the surface of the attractive space where the parameter $\beta$ equals 0.5 . With this simplification, the value of $\beta$ is 1 inside the attractive space and 0 outside. A detailed explanation can be found in [2]. The number of discharges can be represented by equation (1) and (2). Eq. (1) reflects the whole space, while Eq. (2) only the attraction volume. The strike probability of each point in the space is given by Eq. (3).

$$
\begin{aligned}
& N_{F}=\beta N_{G} \int_{V} \frac{d P}{d r} d V, \\
& N_{F a}=N_{G} \int_{V_{a}} \frac{d P}{d r} d V,
\end{aligned}
$$




$$
\frac{d P}{d r}=\frac{k p}{\sqrt{2 \pi} r} \exp \left(-\frac{1}{2} k^{2} p^{2}\left(\ln \frac{r}{r_{m}}\right)^{2}\right)
$$

where $P$ is the probability of the strike at the point $r(\mathrm{~km}) ; k$ is a parameter, which depends on the polarity of lightning; $p$ is usually between 1.2 and 2 (exponent of $\left.I / I_{m}=\left(r / r_{m}\right)^{p}\right)$, see explanation in [2]); $r_{m}$ is the median value of the striking distance; $r$ $(\mathrm{km})$ is the striking distance. $N_{F}$ (strikes/year $/ \mathrm{km}^{2}$ ) represents the whole space and $N_{F a}$ (strikes $/$ year $/ \mathrm{km}^{2}$ ) is for the attractive volume, only.

The dependences of these parameters on different influencing factors (environment, geography, climate and the arrangement of the objects) are necessary to be known for a PMAS simulation.

\section{Case studies}

The polarity-dependence of the attractive space is discussed in detail in numerous publications for single rods, e.g. [1]. In this and the next chapters some case studies are be shown. The attractive space for the top of a single rod is different for the different polarities in a single rod and earth arrangement. This work makes steps towards clarifying how far the attractive space of the wind turbines reaches, what is the value of $\varepsilon=z / h$ ( $z$ is the height of a point of the space, $h$ is height of the examined rod end). Considering the geometry, $\varepsilon$ is 1 , but according to measurements and experiences in the case of positive lightning $\varepsilon>1$, while in case of negative one $\varepsilon<1$.

\subsection{Case studies: effect of the insulating layer}

The focus is on the examination of the effect of the insulating layer on the blades. Therefore, two types of wind turbine models were created for laboratory tests. The first one (Fig. 1a) is made of copper wire with a diameter of $1.5 \mathrm{~mm}$. The length of blades was $s=19.5 \mathrm{~cm}$ and the height of the supporting part was $h=22.5 \mathrm{~cm}$. The endpoints of the blades were rounded. Three main positions were investigated (see Fig. $1 a$ and Fig. 1b). The second type had similar geometry, but the wires had an insulating layer, except at the endpoints of the blades (Fig. 1c).

The downward leader was modeled by a conductive rod and the endpoints of the final jump were recorded. Measurements were carried out with positive and negative polarity. Results were compared with previously published examinations, calculations, measurements and experience with existing wind turbines.

The wind turbine models were placed near a metal rod connected to a standard $1.2 / 50 \mu \mathrm{s}$ impulse generator. The relative position of the endpoint of the rod and the wind turbine model was modified according to a predefined grid (Fig. 2). These measurements are similar to the ones published by Horváth in [10], but the current work represents wind turbines. At each position at least 50 impulses were applied. The number of discharges reaching the endpoints of the blades through the air and the number discharges formed along the blade were recorded. 


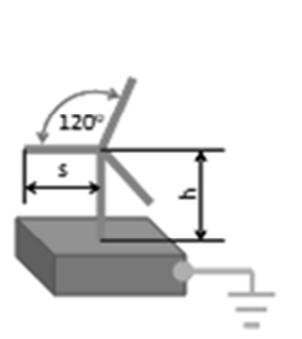

a)

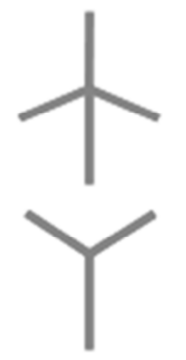

b)

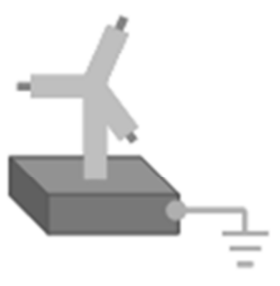

c)
Parameters of the model:

$\mathrm{h}=225 \mathrm{~mm}$

$\mathrm{s}=195 \mathrm{~mm}$

Diameter of the wire $d=1.5 \mathrm{~mm}$

Fig. 1. Simplified models for examination

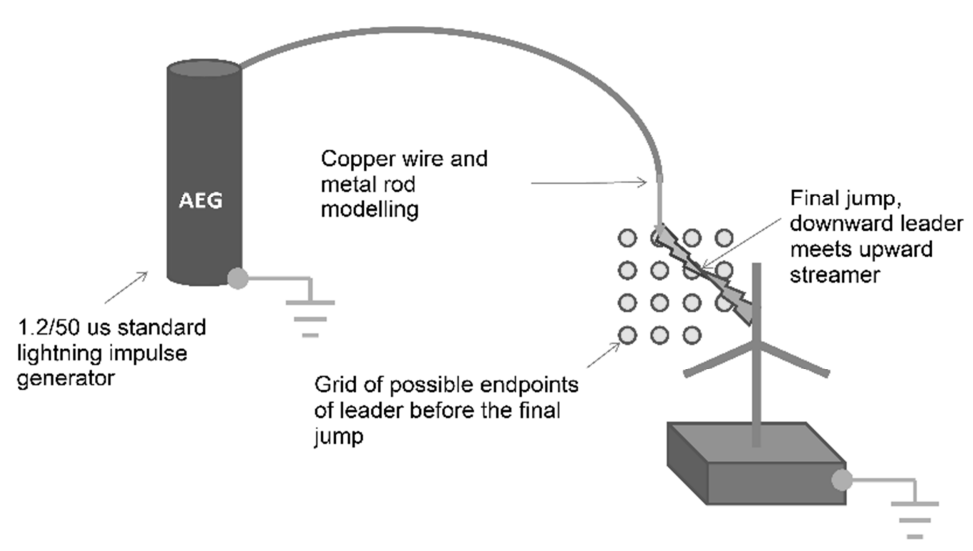

Fig. 2. Schematic drawing about the measurement

\subsection{Case studies: insulating layer on long rod}

A measurement series to examine the attractive space of a long rod $(55 \mathrm{~cm}$ high) with and without an insulating layer was evaluated. This model represents really high, tower like buildings. In this case it is assumed that not every discharge hits into the tip of the rod or the ground, but some incidents in the side of the rod also occur.

A few striking points on the edge of the three attractive spaces were tested (Fig. 3). The goal was to investigate the difference between the calculated (theoretical) and the real attractive space and the effect of the insulator coating. Fifty impulses were used with positive polarity in each measuring point.

In the case without the insulating coating, the distribution of the strikes corresponds with the calculated ones. From the measuring point number 200, the strikes ending at the side of the rod is surprisingly high (Fig. 3). In the case with the insulating coating (Fig. 4), the results were more interesting. The attractive space became very different. The proportion of the discharges, which hit the top of the rod or the ground increased. 


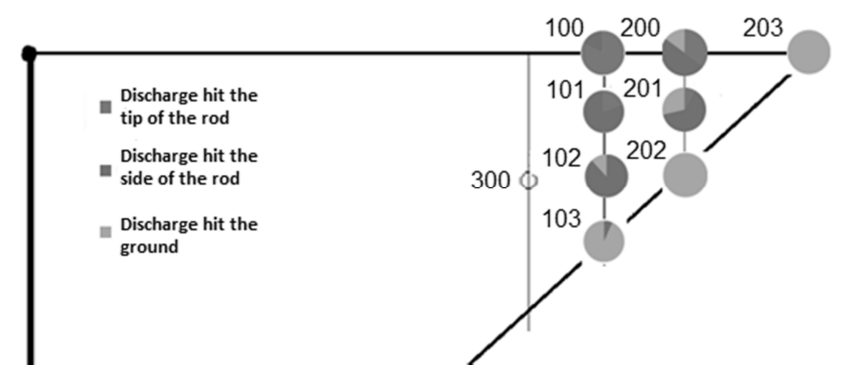

Fig. 3. Discharge rates at different endpoint positions of the high-voltage rod (number denotes the ID of the point), without the insulating coating (positive polarity)

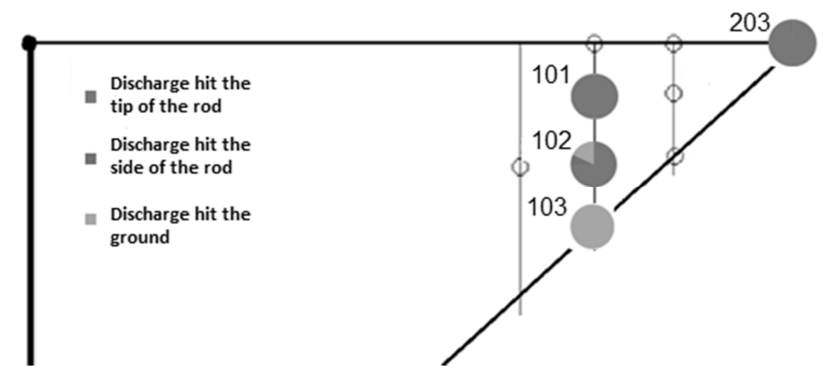

Fig. 4. Discharge rates at different endpoint positions of the high-voltage rod (number denotes the ID of the point), with the insulating coating (positive polarity)

The third measurement series is similar to the previous ones, the difference is that negative polarity was used with more measuring points, and only uninsulated model was applied in this case (Fig. 5).

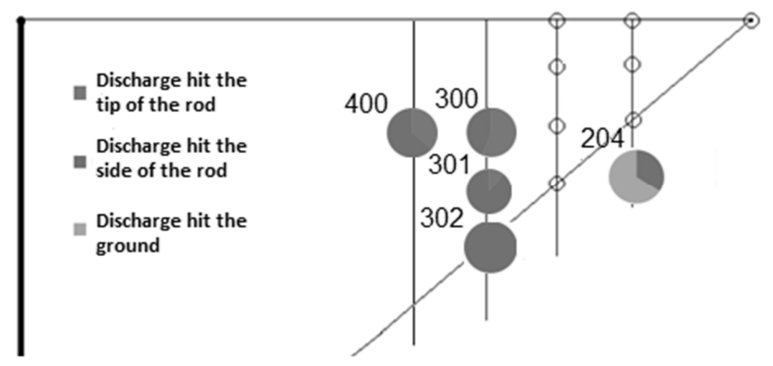

Fig. 5. The measured striking points and the discharge distribution (negative polarity)

It was noticed, that the attractive space belonging to the side of the rod highly decreased, and the space of the ground is also deformed. In the measurement point number 302, at the edge of the attractive space ground discharge was not observed, while in the point number 204, the space of the ground was clearly dominant, still several discharges were observed at the side of the rod (Fig. 5). 


\section{Representation of results}

Taking into consideration the geometry only, the boundary of the attractive space bounded by line 1) in Fig. 6 (points inside the area bordered by line 1) are closer to the side of the blades than to the tips). Unfortunately, the real boundary significantly differs from the previous one and the difference depends on the polarity.

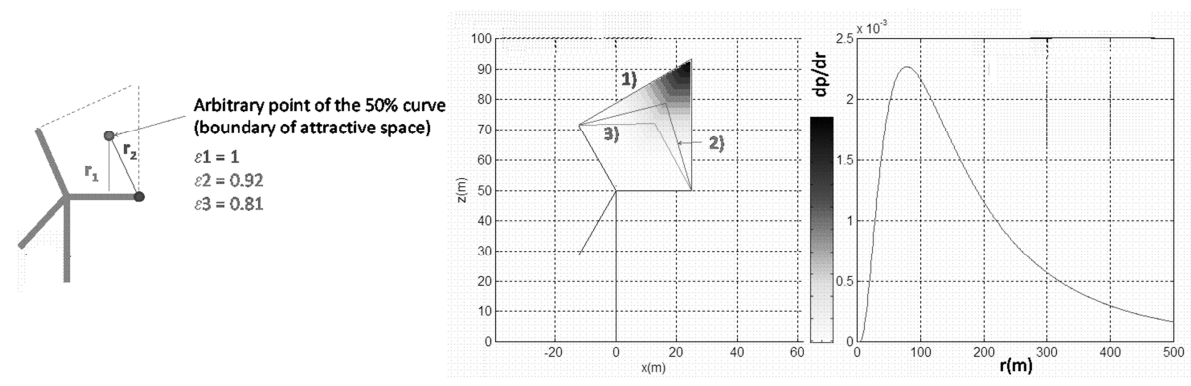

Fig. 6. Simplified models for examination, 2D section of a 3D attraction volume

It was found, that for lightning of negative polarity the tips receive significantly more strokes than the side of the blade compared to the positive polarity, therefore further analysis was made with positive impulses.

The high value parts of the $d P / d r$ are concentrated at the end of the blades. Accordingly, the ends of the blades give the same results for calculations and measurements.

Fig. 6 shows the change of the boundary of attractive space of the side of the blade for positive polarity when the wind turbine model is purely conductive (line 2) and when the surface is covered by an insulating layer (line 3). It can be seen, that the presence of the insulating layer reduces the attractive space.

The received result shows well that most of the damage occurs near the end of the blades. Closer to the top of the blades is the highest probability of a strike, accordingly the number of strokes in a $d V$ volume. This result shows that for higher wind turbines only one receptor is not enough. The IEC 61400-24 standard [11] provides the number and distance of the receptors. Similar multi-receptor composition was examined by Madsen [12].

\section{Measurements for multi-receptors}

Another arrangement was created to examine a two-receptor wind turbine model. In this case two metallic contacts of insulated copper wire were created (Fig. 7a) on the test-object [13], [14].

If there is conductive wire and it is divided into two parts, then the border of the attractive space of each part is presented by the grey thin lines. In this case the blades are made of insulating material and each points $(1,2,3,4)$ represent a receptor, the attractive space of section 1-2, 2-x, $x-3$ and 3-4 will be separated by the grey dashed 
line. The point marked with ' $\mathrm{O}$ ', is equal distance from the four points (1-4), but the closest objects are the insulated parts of the blades.

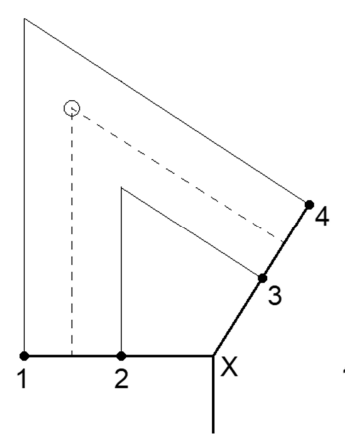

a)

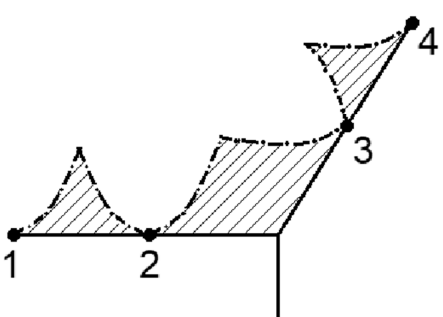

b)

Fig. 7. The attractive space for the case of two receptors, a) theoretical, b) corrected

During the measurement, positive polarity impulses were 25-times applied. In the first series, 21 from 25 strokes into the $4^{\text {th }}$ point and the other 4 ones stroke into the $3^{\text {rd }}$ point. But in this case the end of the electrode was a little bit closer to these points. Therefore, another series were developed and a correction was made. After that, the number of the strikes hitting the points was: $1^{\text {st }} 2,2^{\text {nd }} 3,3^{\text {rd }} 1$ and $4^{\text {th }} 16$. Besides that, 3 strikes were observed, which hit between the $1^{\text {st }}$ and $2^{\text {nd }}$ points into the insulated part. This observation is of high importance, because it shows that the attractive space of the blades is not negligible. Fig $7 b$ represents the situation, when an arbitrary point is considered to be part of the attractive space of the closest object. With this assumption, attractive space of receptors 2 and 3 would be only 2 sections of lines, which contradicts the experience and the results of the laboratory measurements.

Considering that receptors have a length of $d x$, the lines become $d x$ wide sections, but the integrals of $d P / d r$ values for that volume still give too low results. After the modification of the attractive space as it is shown in Fig. $7 a$ a much better accordance between the calculated and measured results was obtained. In this case the attractive space of the surface of insulated blades is reduced as it can be seen in Fig. 7 b.

It must be noted, when the surfaces of the blades are completely neglected (in other words, only receptors exist), the boundary between the attractive space of the receptors in the represented cross-section is denoted by the black solid line (Fig. 7a).

\section{Laboratory arrangements for simulation issues}

In order to apply the PMAV method, it is necessary to know the surface of $50 \%$ probability (the interface of the attractive volume). During each measurement, the goal is to determine [15] the value of $\varepsilon$. In the case of high buildings this is important, because it allows comparing the regular case of downward leaders with the upward initiated leaders, appearing in huge number for high structures. 
If the upward initiated leader is started by the electric field of the space charge in the thunder cloud, in contrast with the case of downward-leader, the stroke cannot be determined with this known method. These examinations were investigated by Madsen et al. [13] with wind turbines. In those arrangements, they have connected metal plates to a high voltage impulse generator. The examined object was placed under the high voltage electrode. Similar arrangement is shown in Fig. 8 (left).
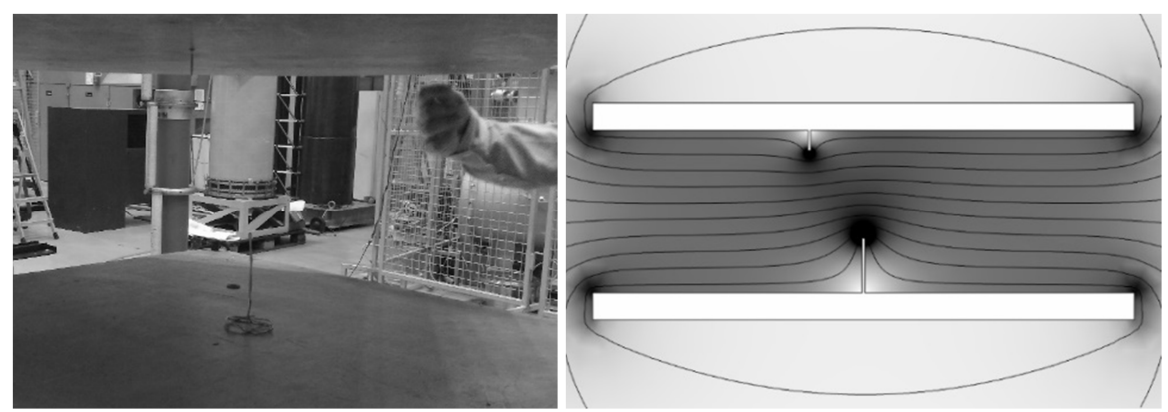

Fig. 8. Left: Arrangement (plane-plane with the tower and the pre-discharge); Right: Simulation of the arrangement ( $\mathrm{E}$ and $\mathrm{U}$ in the moment of the peak)

Although the phenomenon itself is well-known for experts of this specialization, it is still surprising that in case of standard $1.2 / 50 \mu \mathrm{s}$ impulse the discharge does not always occur between the object and the high voltage electrode.

Four different simulations were carried out in order to find the arrangement that shows satisfactory accordance with the measurements:
A. plane - plane (arrangement I);
B. Rogowski - plane (arrangement II-A);
C. Rogowski with torus - plane (arrangement II-B);
D. Arrangement of Horváth (arrangement III).

\subsection{Normal arrangements}

In the computer simulations (Fig. 8 (right), Fig. 9 (left), Fig. 10, Fig. 11 (right)), the moment of the peak of the impulse voltage were visualized. In the figures, the equipotential lines are symbolized by the voltage $(U)$ and the grey-scale palette marks the norm of the electric field vectors $(E)$. The black belongs to the highest and the white the lowest values.

It is clearly visible that the density of the electric flux is the highest at the rounded (with small radius) parts [16] that cause incorrect conclusions from the measurements.

To eliminate the error due to the finiteness of the planes and to decrease the inhomogeneity of the field, a Rogowski-plane arrangement was used (Fig. 9, left). In this experiment the expected values were closer to the theoretical ones, but an interesting phenomenon occurred. Some discharges initiated at the end of the Rogowski electrode along the electric field strength line in a low field regime (Fig. 9, right). 

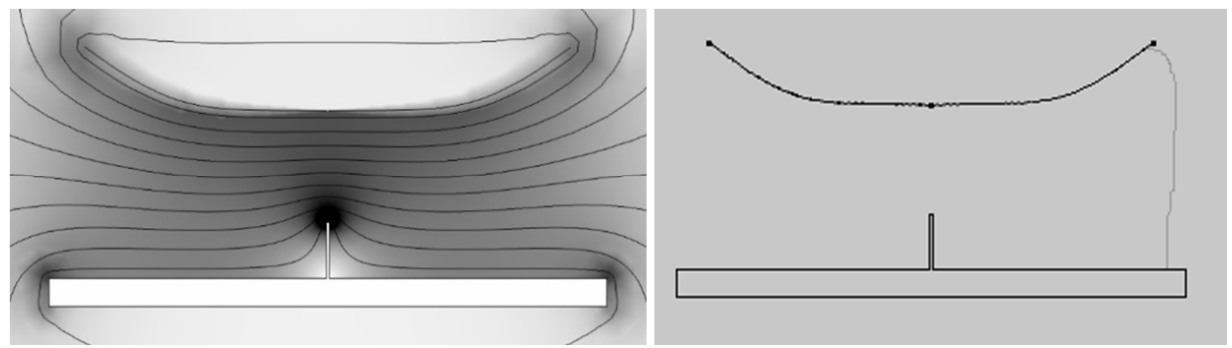

Fig. 9. Left: Simulation for the arrangement (E and $U$ in the moment of the peak), Right: The experiment during the measurement- discharges near the border of the Rogowski electrode

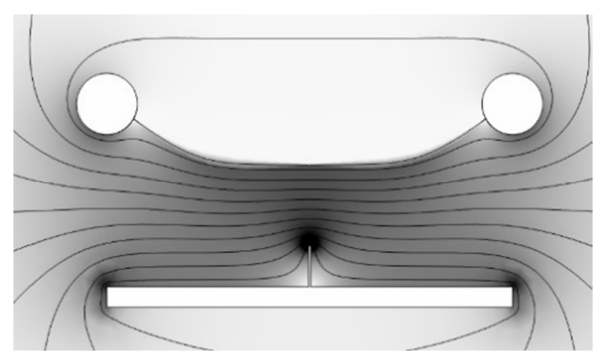

Fig. 10. Simulation for the arrangement ( $\mathrm{E}$ and $\mathrm{U}$ in the moment of the peak)
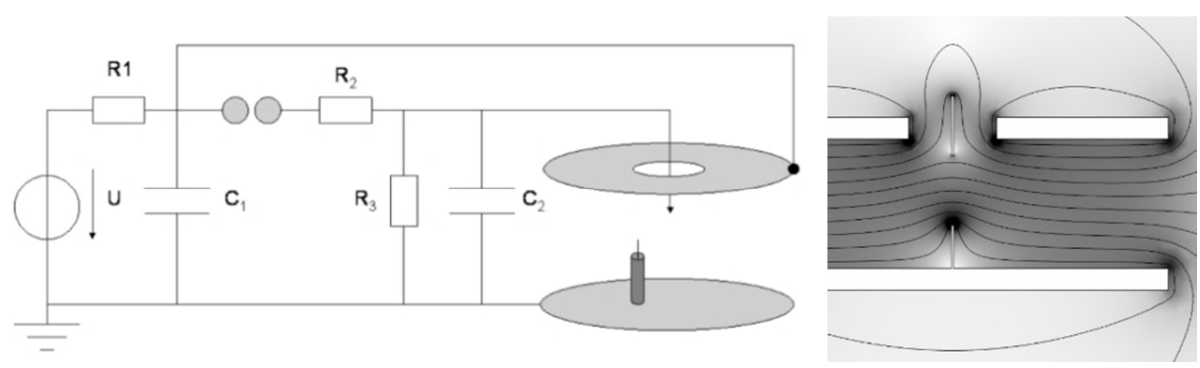

Fig. 11. Left: Recommended arrangement for tall buildings, [8], Right: Simulation for the arrangement ( $\mathrm{E}$ and $\mathrm{U}$ in the moment of the peak)

The decrement of the electric field in the critical points can be seen (Fig. 9). Another solution could be reached when a torus is put on the Rogowski electrode (Fig. 10). Although the models are smoother, but they have shortages: the charge of the cloud cannot be represented.

\subsection{Modified arrangement with represented cloud charge}

In this arrangement (Fig. 11), the charge of the clouds was represented by a plane above the earthed plane having a hole in the middle. The plane was connected to the first charging stage (DC voltage) of the impulse generator. A rod connected to the 
impulse generator output was put through the hole, representing the downward leader. In this case, the edges of the planes distort the electric field, but there is a separated electrode for the downward-leader and for the cloud; this results in a model much closer to the arrangement found in nature.

\section{Laboratory experiments}

Laboratory measurements were evaluated in parallel with the computer simulations. Two cases were distinguished in Table I depending on the location of the discharge.

\section{Table I}

The result of the laboratory measurements

\begin{tabular}{|c|c|c|c|l|}
\hline \multirow{2}{*}{ Polarity } & \multirow{2}{*}{ Arrangement } & \multicolumn{2}{|c|}{ Number of the discharges } & \multirow{2}{*}{$\begin{array}{l}\text { A. between the two } \\
\text { electrodes ('tower' }\end{array}$} \\
\cline { 3 - 4 } & & A & B & and 'pre-discharge'); \\
\hline- & plane-plane & $23(92 \%)$ & $2(8 \%)$ & \\
- & Rogowski-plane & $25(100 \%)$ & $0(0 \%)$ & B. between other \\
+ & plane-plane & $5(20 \%)$ & $20(80 \%)$ & points \\
+ & Rogowski-plane & $0(0 \%)$ & $25(100 \%)$ & \\
\hline
\end{tabular}

It is possible to arrive to the conclusion that the experienced and the expected number of strikes hitting the blade are non-negligible neither in the case of positive nor negative polarity. Most of the discharges occur between the rod representing the predischarge and the grounded plane. There were some cases when the discharges hit close to the 'tower' but into the ground.

\section{Role and significance of the breakdown voltage}

A direct relationship is assumed between the current and the striking distance. Between these two, a relationship is given by the $I / I_{m}=\left(r / r_{m}\right)^{p}$ equation through the constant $p$. For the sake of simplicity, it is necessary to stay at this hypothesis. A higher current results in a higher striking distance, too.

Fig. 12 shows the striking point (O) for different impulse voltages, when the breakdown is different from the ideal voltage. In this case the breakdown is occurring on the front of the impulse, therefore the striking point $(\mathrm{O})$ migrates to the point $(1),(2)$ or (3) and the measurements give misleading results.

In case of low building $(10-20 \mathrm{~m})$, the downward-leaders are dominant, and in this case the charge of the cloud is negligible. With the increasing height of the building, this will be non-negligible, and therefore it is necessary to consider the Arrangement III, where the charge of the lower layer of the cumulonimbus is represented (Fig. 12).

\section{Conclusion}

The result of the research shows that rethinking of the principles and basic assumptions may be necessary. Many wind turbines are exposed to special lightning 
phenomena, like winter lightning, which is experienced in large numbers on the Japanese coast.
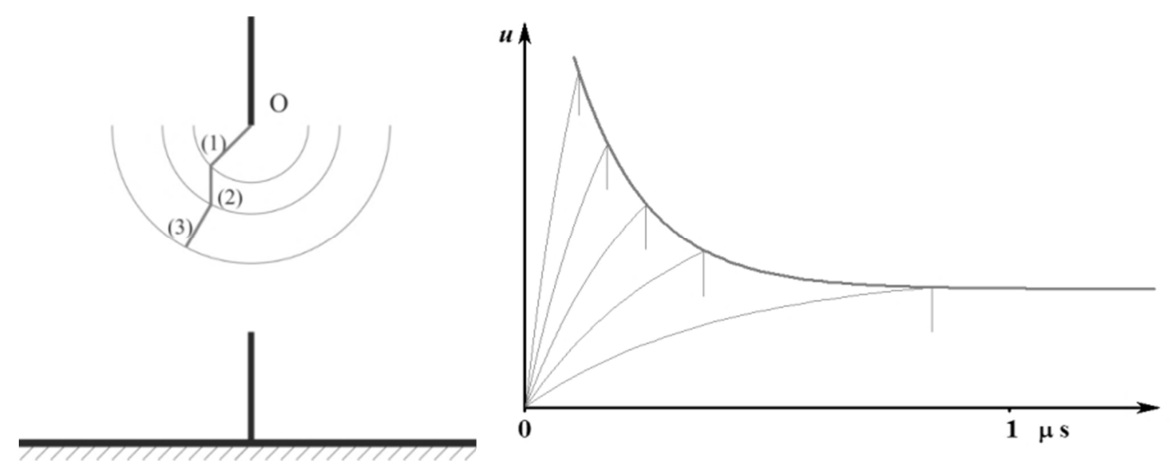

Fig. 12. Left: The striking point in 3 different points, when the voltage of the impulse is too high, Right: The breakdown voltage in time (on the basis of [2]).

In certain cases, most of the lightning strikes, which hit the wind turbines, hit the first third of the blades. One possible case is when the lightning current is extremely high, and its Joule-heat damages the down-conductor. Other case is, when it does not hit into the receptors, but also the lightning hits into the conductor running under the insulating cover.

During the laboratory measurements, it is possible to come to a wrong conclusion due to the inaccurate arrangements and not carefully chosen conditions. Considering all these facts, it is advisable to prepare the measurements carefully and recognizing their complexity. The simplifications used in the simulations should be validated by comparison with actual measured values.

\section{Open Access statement}

This is an open-access article distributed under the terms of the Creative Commons Attribution 4.0 International License (https://creativecommons.org/licenses/by/4.0/), which permits unrestricted use, distribution, and reproduction in any medium, provided the original author and source are credited, a link to the CC License is provided, and changes - if any - are indicated. (SID_1)

\section{References}

[1] Bertelsen K., Erichsen H. V., Madsen S. F. Application of numerical models to determine lightning attachment points on wind turbines, International Conference on Lightning and Static Electricity, Paris, France, 27-31 August 2007.

[2] Horváth T. Computation of lightning protection, John Wiley, 1990. 
[3] Horváth T. Interception efficiency of lightning air termination systems constructed with rolling sphere method, 28th International Conference on Lightning Protection, ICLP 2006, Kanazawa, Japan, 18-22 September 2006, pp. 555-560.

[4] Sorensen T. S., Plumer J. A., Montanyà J., Krogh T. H., Hermoso B., Birkl J., Gehlhaar T., McNiff B., Bertelsen K., Peesapati V. : The update of IEC 61400-24 lightning protection of wind turbines, Proc. of 29th International Conference on Lightning Protection, Uppsala, Sweden, 23-26 June 2008, pp. 10-13.

[5] Napolitano F., Paolone M., Borghetti A., Nucci C. A., Cristofolini A., Mazzetti C., Fiamingo F., Marzinotto M. Models of wind-turbine main-shaft bearings for the development of specific lightning protection systems, IEEE Trans. on Electromagnetic Compatibility, Vol. 53, No. 1. 2011, pp. 99-107.

[6] Yokoyama S., Honjo N., Yasuda Y. Causes of wind turbine blade damages due to lightning and future research target to get better protection, Proc. of International Conference on Lightning Protection, Shanghai, China, 11-18 October 2014, pp. 551-558.

[7] Cummins K. L., Quick M. G., Rison W., Krehbiel P., Thomas R., Rodeheffer D., Warner T. A., Saba M. M .F., Schumann C., Myers J., Lyons W., Nag A., Cramer J., Turner T., Samaras T., Samaras P., Young C., Mcharg G., Engle J., Cummer S. A., Lu G. Overview of the Kansas wind-farm 2013 field program, XV International Conference on Atmospheric Electricity, 15-20 June 2014, Norman, Oklahoma, USA, p. 16.

[8] Masden S. F., Bertelsen K., Krogh T. H., Erichsen H. V., Hansen A. N., Lonbaek K. B. Proposal of new zoning concept considering lightning protection of wind turbine blades, Journal of Lightning Research, Vol. 4, 2012, pp. 108-117.

[9] Kiss I., Németh B., Horváth T. Improved method for the evaluation of shielding effect of objects near medium voltage transmission lines, Proc. of the International Conference on Lightning Protection, ICLP 2014, Shanghai, China, 11-18 October 2014, pp. 1780-1785.

[10] Hannig M., Hinrichsen V., Hannig R. An analytical consideration on the striking probability and the total amount of strikes to simple structures according to standardized regulations, International Conference on Lightning Protection, ICLP 2014, Shanghai, China, 11-18 October 2014, pp. 1343-1350.

[11] IEC 61400-24:2010, Wind turbines, Part 24: Lightning protection, International Electrotechnical Commission, 2010.

[12] Horváth T., Pankasz L. Ermittlung der Wahrscheinlichkeiten von Nahe- und Seiteneinschläge bei Fernsehturm Moskau durch Modellversuche, Proc. of the International Conference on Lightning Protection, ICLP 1978, Gdansk, Poland, 22-26 May 1978, Paper 12.

[13] Madsen S. F., Mieritz C. F., Candelela Garolea A. Numerical models to determine lightning attachment point distributions on wind turbines according to the revised IEC 61400-24, International Conference on Lightning and Static Electricity, (ICOLSE), Pittsfield, USA, 15-17 September 2009, Paper SEA13-2.

[14] Tóth Z., Kiss I. Evaluation of striking frequency in case of wind turbines with multiple receptors, 4th International Symposium on Winter Lightning, ISWL 2017, Joetsu, Japan, 12-14 April 2017, Paper TZ_K, p. 6.

[15] Iványi P. Parallel conversion of element meshes, Pollack Periodica, Vol 9, No. 3, 2014, pp. 89-102.

[16] Marcza D., Kuczmann M. Parallel solution of an electrostatic field problem - case study, Pollack Periodica, Vol 7, No. 2, 2012, pp. 25-34. 